


\title{
Evaluation of Shear Bond Strength of a Grander-Modified Adhesive System to Bovine Dentin
}

\author{
Daniel Gomes Duarte, Sérgio Eduardo de Paiva Gonçalves, Daphne Câmara Barcellos \\ Maria Filomena Rocha Lima Huhtala, Eduardo Bresciani, Cesar Rogério Pucci
}

\section{ABSTRACT}

Purpose: The objective of this study was to evaluate the influence of the Grander technology on the shear bond strength of total-etch adhesive system Single Bond 2 to dentin.

Materials and methods: Forty bovine incisors were used. They were sectioned and the buccal surfaces worn down with abrasive paper. Acid etching was performed, and the specimens were divided into two groups ( $n=20$ ): Group G1-Single Bond 2 adhesive system (3M ESPE) under normal conditions; group G2-Single Bond 2 adhesive system modified by physical contact for 48 hours with the flexible unit Grander system. The resin composite was inserted with the aid of a metallic matrix over the prepared area. After the mechanical shear test, data were submitted to the statistical t-test $(5 \%)$. The t-test showed that the results for $\mathrm{G} 1$ and $\mathrm{G} 2$ were similar $(p>0.05)$. The mean values $( \pm \mathrm{SD})$ were: $\mathrm{G} 1-6.66( \pm 2.40)$; $\mathrm{G} 2-5.26( \pm 2.15)$.

Conclusion: Grander technology did not influence the initial shear bond strength of the Single Bond 2 adhesive system to dentin.

Keywords: Grander technology, Shear bond strength, Adhesive system.

How to cite this article: Duarte DG, de Paiva Gonçalves SE, Barcellos DC, Huhtala MFRL, Bresciani E, Pucci CR. Evaluation of Shear Bond Strength of a Grander-Modified Adhesive System to Bovine Dentin. World J Dent 2012;3(2):176-179.

Source of support: Nil

Conflict of interest: None declared

\section{INTRODUCTION}

The formation of the hybrid layer is directly related to the surface treatment of substrate and to the intrinsic characteristics of adhesive systems. The acid etching procedure to dentin leads to great variations on the chemical composition and physical properties of the dentin matrix. Those alterations may interfere in the quality and resistance of dentin-resin adhesion, and consequently in its durability. ${ }^{1-3}$ Moreover, the surface wettability, an intrinsic characteristic of the adhesive systems determined by their surface tension, also influences directly the quality of adhesion due to their diffusibility over the modified substrate. ${ }^{4}$

Grander has developed a technology able to 'revitalize' water by electromagnetic implosion by energy resonance, without the use of electricity or magnets. The process reorganizes the molecules of liquids into smaller polymeric units. The surface tension is one of the modified properties when this technology is used ${ }^{4-6}$ (Gonçalves 2). The Grander device presents a closed system, composed of interior armored cylinders and water with altered electromagnetic structure. This water possesses an internal structure that enables it to absorb as well as to radiate very small energy spectra to water circulating through the device. ${ }^{7}$

It is known the lower surface tension of an adhesive, the greater its wettability and consequently improved monomer penetration into the demineralized substrate is obtained. ${ }^{8-11}$ In 2005, Gonçalves et a ${ }^{12}$ performed the first study about the applicability of the Grander technology on dental adhesive systems. They observed a reduction on the surface tension at around $10 \%$, a reduction of the contact angle, and the maintenance of previous hybridization characteristics.

Stimulated by previous observations, the present study aimed to evaluate the shear bond strength to bovine dentin of a total-etch single bottle adhesive system (Single Bond 3M) modified by the Grander technology, and also to assess by stereomicroscopy the mode of failure at the dentin/ restorative material interface.

\section{MATERIALS AND METHODS}

The commercial name, chemical composition, bath number and manufacturers of the material used are presented in Table 1.

Forty extracted bovine incisors were used in the study. They were cleaned and stored in distilled and deionized water at $-18^{\circ} \mathrm{C}$ prior to use. The roots were sectioned with a steel diamond disk (KG Sorensen, Rio de Janeiro, Brazil) at the cement-enamel junction. The buccal surfaces were worn using abrasive papers (granulation 400) coupled to a circular polishing machine (PA-10, Panambra, São Paulo, Brazil) under water cooling, to expose an area of dentin. An opening was made on the lingual surface using a round diamond bur \#1012 (KG Sorensen, Rio de Janeiro, Brazil) to allow measurement of the amount of remaining dentin. The remaining dentin thickness was assessed by means of a caliper (Golgran, São Caetano do Sul, Brazil) and standardized at $2 \mathrm{~mm}$ by wearing the dental surface. The openings at the lingual surface and root canal were clogged with utility wax (Polidental, Cotia, SP, Brazil). The worn buccal areas were embedded in colorless acrylic resin 
Evaluation of Shear Bond Strength of a Grander-Modified Adhesive System to Bovine Dentin

Table 1: Commercial name, composition, bath number and manufacturer of the material used

\begin{tabular}{|c|c|c|c|}
\hline Commercial name & Composition & Batch number & Manufacturer \\
\hline Acid & $35 \%$ phosphoric acid gel & 7523 & 3M ESPE, St Paul, MN, USA \\
\hline Flexible unit & Stainless steel and Grander water & - & $\begin{array}{l}\text { Grander Technologies, Jochberg, } \\
\text { Austria }\end{array}$ \\
\hline $\begin{array}{l}\text { Adper Single Bond } \\
2 \text { adhesive }\end{array}$ & $\begin{array}{l}\text { Copolymers of polyacrylic and } \\
\text { polyitaconic acids, water, } \\
\text { ethanol, photoinitiators }\end{array}$ & 51202 & 3M ESPE, St Paul, MN, USA \\
\hline $\begin{array}{l}\text { Filtek Z250 } \\
\text { composite }\end{array}$ & $\begin{array}{l}\text { Bis-GMA, UDMA, TEGDMA, } \\
\text { Bis-EMA, zirconia/silica }\end{array}$ & 13701 & 3M ESPE, St Paul, MN, USA \\
\hline
\end{tabular}

(Classic, São Paulo, Brazil). The smear layer was standardized using abrasive papers with granulations of 600 , 1200 and 1600, coupled to a circular polishing machine.

\section{Modification of Adhesive System by the Grander System}

Two sets of the same batch of Single Bond 2 adhesive system (3M ESPE, St Paul, MN, USA) were used. One set was kept unchanged (control). The second bottle (experimental) was placed in physical contact with the Grander system flexible unit (Grander Technologies, Jochberg, Austria). This system consists of a device named flexible unit, capable of revitalizing water by electromagnetic induction resulting in molecular rearrangement. The Grander technology can be applied through contact with bottles of liquid or by the passage of liquids through the interior channels placed among cylinders which compose the core of the unit. The second bottle (experimental) of the adhesive system was placed in contact with the flexible unit for 48 hours.

\section{Adhesive Procedures}

The dentin surfaces were etched with $37 \%$ phosphoric acid gel for 15 seconds. The specimens were then washed with air/water spray for 30 seconds to expose the dentin tubules, and the excess moisture was removed with absorbent paper.

The specimens were divided into two groups according to the adhesive system used. Each group was composed of 20 specimens:

- Group 1 (control): Single Bond 2 adhesive system (3M ESPE) was applied according to the manufacturer's recommendations;

- Group 2 (experimental): Single Bond 2 adhesive system (3M ESPE) modified by Grander system was applied according to the manufacturer's recommendations.

To standardize the resin composite area and volume, a prefabricated metallic device $3 \mathrm{~mm}$ in diameter and $4 \mathrm{~mm}$ high was used. The device was positioned over the dentin surface that received the adhesive treatment, and did not allow the set to be displaced while the resin composite was inserted and light cured. Resin composite was inserted using the incremental technique, and cured with a lightcuring unit calibrated at $500 \mathrm{~mW} / \mathrm{cm}^{2}$ (Curing Light XL 3000/3M ESPE).

The specimens were removed from the metallic device and lightcured for an additional 40 seconds. A resin composite cylinder adhered to the dentin surface that received the adhesive treatment was obtained. The specimens were immersed in distilled water at room temperature and stored at $37^{\circ} \mathrm{C}$ for 48 hours.

\section{Shear Bond Strength Test}

For the shear strength test, the specimens were fixed to a metallic base, in order to correctly adapt them to the Instron machine (model 431-Instron Corporation). A $50 \mathrm{~kg}$ load cell was used and the crosshead speed was set at $0.5 \mathrm{~mm} /$ minute. The fracture force was recorded. After the shear strength testing, the specimens were submitted to optic microscopy analysis (Zeiss/Stemi 2000C) and classified into four types, according to the section plane of the fracture involved: Type I-cohesive fracture in resin composite; type II-cohesive fracture in dentin; type III-adhesive fracture at the dentin/adhesive or adhesive/resin interface and type IV - mixed fracture (combination of cohesive and adhesive fracture).

Data were submitted to the statistical t-test at a $5 \%$ level of significance.

\section{RESULTS}

No significant difference between both groups was detected by the t-test $(\mathrm{t}=1.95 ; \mathrm{p}=0.059)$.

The mean and standard deviation values of both groups, as well as the type of fractures observed after testing are presented in Table 2. The examination of specimens indicated predominantly mixed fractures for both groups.

Considering the frequency of the mixed type fracture, no significant difference between the groups was detected by the t-test $(\mathrm{t}=1.28, \mathrm{p}=0.218)$. The same observation is 
Table 2: Distribution of type of fracture $(\mathrm{N})$ and mean (in $\mathrm{MPa}$ ) and standard deviation (SD) values for both groups

\begin{tabular}{|c|c|c|c|c|}
\hline \multirow[t]{2}{*}{ Fracture type } & \multicolumn{2}{|c|}{ Group 1 (control) } & \multicolumn{2}{|c|}{ Group 2 (experimental) } \\
\hline & $N$ & Mean $\pm S D$ & $N$ & Mean $\pm S D$ \\
\hline Adhesive & 2 & $9.27 \pm 4.62$ & 0 & - \\
\hline Cohesive & 7 & $5.64 \pm 1.99$ & 9 & $4.92 \pm 1.31$ \\
\hline Mixed & 11 & $6.83 \pm 2.07$ & 11 & $5.52 \pm 2.69$ \\
\hline
\end{tabular}

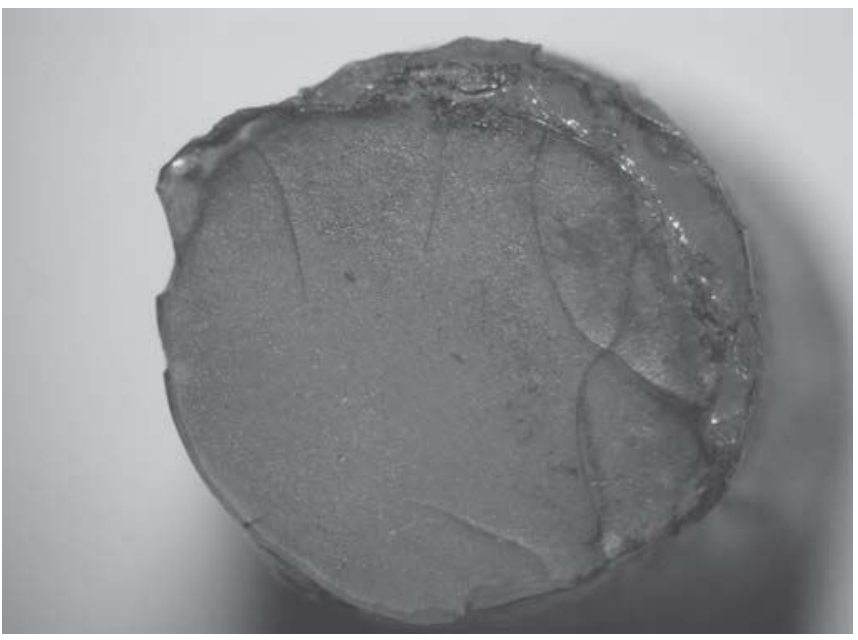

Fig. 1: Example of mixed fracture

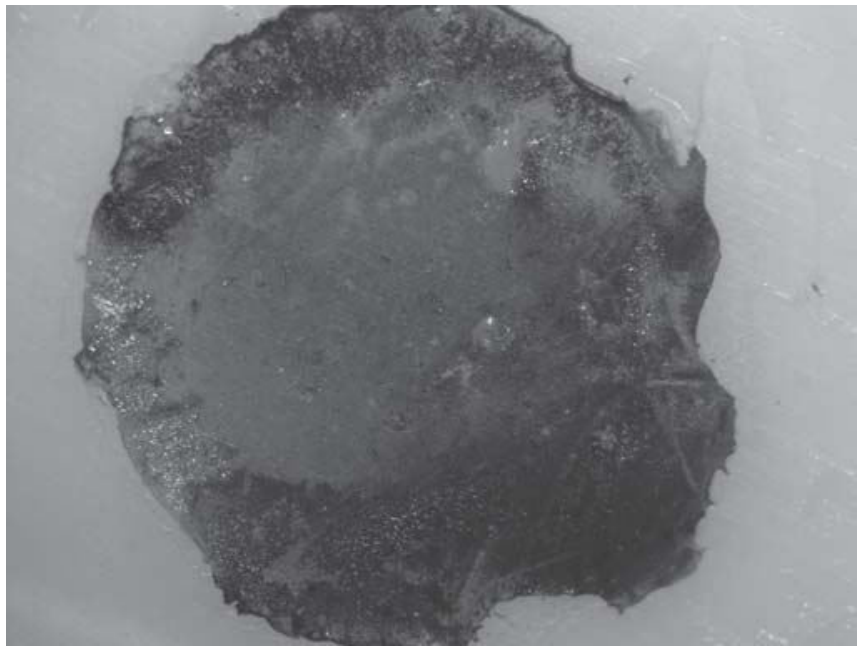

Fig. 2: Example of cohesive fracture

valid for the frequency of cohesive fractures, with no significant difference between the groups detected by t-test $(\mathrm{t}=0.82, \mathrm{p}=0.431)$.

Figures 1 and 2 show examples of mixed and cohesive type fractures respectively.

\section{DISCUSSION}

The present study was conducted to evaluate the influence of the Grander technology on Single Bond 2 total-etch adhesive system, assessing the shear bond strength at the interface of bovine dentin substract and resin composite. The two-step adhesive system (Single Bond) used presents hydrophilic characteristics, and it should be applied on dentin surface after treatment with $35 \%$ phosphoric acid. ${ }^{9,13,14}$

The acid etching procedure promotes both an increase and a decrease of surface energy, when the substract is enamel or dentin respectively The adhesive system must present lower surface tension than the surface-free energy of the conditioned dentin, once the wettability of the adhesive is a preponderant factor for the penetration of the monomer into the demineralized dentin. ${ }^{9,14}$ It is known the greater the permeability of the demineralized intertubular dentin, the better the diffusion of adhesive monomers. This fact influences the formation of resin tags in the interior of the dentin tubules and hybrid layer within the intertubular dentin. The incorporation of solvents into adhesive systems improves the diffusion of monomers in between the remaining collagen fibrils, fact that is improved by the permeability of the dentin., ${ }^{4,5,12}$

In a study performed by Klaus Faisnner, ${ }^{7}$ the chemical and physical-chemical properties of water revitalized by Grander process were compared to the primary nonrevitalized form of water. Among the several tested parameters including: Ionic balance, density, electrical conductivity, $\mathrm{pH}$, surface tension, tests with toluene and methanol, vapor-liquid equilibrium, and boiling diagram, the surface tension was the single parameter presenting statistical differences, with a $10 \%$ reduction for the revitalized water. Gonçalves ${ }^{12}$ in 2005 , similarly detected a $10 \%$ reduction of the surface tension of both adhesive systems tested, Single Bond and Clearfil SE Bond.

There was an increase of wettability of the adhesive system when Grander modified, fact that was detected visually and by handling assessment. This result led to a more fluid adhesive system, which theoretically would present greater interlocking between the adhesive and demineralized dentin. However, both tested groups of the present study behaved similarly in relation to the initial adhesive bond strength and also according to the type of observed fracture between the dentin substrate and the resin composite. Further investigations are necessary to determine the properties and characteristics of adhesive systems undergone Grander modification, and also to determine the influence of the Grander technology on the bond strength at a long-term basis. 
Based on the obtained results, we were able to verify that Grander modification of Single Bond adhesive was not deleterious for the initial adhesive strength, fact that is initially considered a positive outcome. The water revitalization process proposed by the Grander system is interesting, once the equilibrium obtained by water revitalization is longitudinal and not an immediate outcome. Thus, based on the present outcomes, we suggest more studies should be performed to evaluate the long-term effects of the Grander technology on the total-etch Single Bond and self-etching adhesive systems.

\section{CONCLUSION}

Based on the methodology employed, it can be concluded the Grander technology does not influence the shear bond strength to dentin substrate using Single Bond 2 adhesive system.

\section{ACKNOWLEDGMENT}

The authors thank the São Paulo State Research Support Foundation- 'Fundação de Amparo à Pesquisa do Estado de São Paulo - FAPESP' for the financial support.

\section{REFERENCES}

1. Gonçalves SEP, Araujo MAM, Damião AJ. Dentin Bond strenght: Influence of laser irradiation, acid etching and hypermineralization. J Clin Med Surg 1999;17:77-859.

2. Pashley DH, Zhang Y, Agee KA, Rouse CJ, Carvalho RM, Russell CM. Permeability of demineralizated dentin to HEMA. Dent Mater 2000;16:7-14.

3. Perdigão J, Lambrechts P, Van Meerbeek B, Braem M, Yildiz E, Yücel T, Vanherle G. The interaction of adhesive systems with human dentin. Am J Dent 1996;9:167-73.

4. O'brie, WJ, Ryge G. Surface and adhesion phenomens. In Materiais Dentários. Rio de Janeiro: Interamericana, 1981.

5. Gonçalves SEP, Burim RA, Pleffken PR, Barcellos DC, Gomes APM, Huhtala MFRL. A comparative study of the physical properties of conventional and Grander-modified adhesive systems. J Dent Sci 2011;26(4):315-20.

6. Gonçalves SEP, Matias DT, Barcellos DC, Huhtala MFRL, Silva TM, Balducci I, Torres CRG. Influence of the Grander technology in the physical properties of the self-etch adhesive system. World J Dent 2012;3(1):1-5.

7. Faissner K. Physical and physical-chemical data in the application of revitalized and non-revitalized water and the use of Grander water revitalization in industry. March, 2000. [serial online] Available at: http://www.grander-tecnologie.com/en/ wissenschaft-forschung/DiplomarbeitUniGrass.php. Accessed May 26, 2011.

8. Nakabayashi N. Dentinal bonding mechanisms. Quintessence Int $1991 \mathrm{Feb} ; 22(2): 73-74$.
9. Pashley DH, Horner JA, Brewer PD. Interactions of conditioners on the dentin surface. Oper Dent 1992(Suppl 5):137-50.

10. Saboia VP, Rodrigues AL, Pimenta LA. Effect of collagen removal on shear bond strength of two single-bottle adhesive systems. Oper Dent 2000;25(5):395-400.

11. Titley K, Caldwell R, Kulkarni G. Factors that affect the shear bond strength of multiple component and single bottle adhesives to dentin. Am J Dent 2003 Apr;16(2):120-24.

12. Gonçalves SEP, Crus N, Brayner R, Huhtala MFRL, Borges $\mathrm{AB}$, Barcellos DC. Grander system - a new technology to reduce surface tension of adhesive systems in dentistry. 2011; No prelo.

13. Gonçalves SEP, Araujo MAM, Padilha RQ. Multipurpose adhesives: Evaluation of bond strength to dentin by the shear test. Braz Dent Sci 1996;25:113-21.

14. Nakabayashi N, Nakamura M, Yasuda N. Hybrid layer as a dentin-bonding mechanism. J Esthet Dent 1991;3(4):133-38.

\section{ABOUT THE AUTHORS}

\section{Daniel Gomes Duarte}

Graduate Student of the National Institute for Space Research (INPE) Diamonds and Related Materials, Dimare Group, São José dos Campos, Brazil

\section{Sérgio Eduardo de Paiva Gonçalves}

Associate Professor, Department of Restorative Dentistry, São José dos Campos School of Dentistry, São Paulo State University São Paulo, Brazil.

\section{Daphne Câmara Barcellos}

PhD Student, Department of Restorative Dentistry, São José dos Campos School of Dentistry, São Paulo State University, São Paulo Brazil

\section{Maria Filomena Rocha Lima Huhtala}

Assistant Professor, Department of Restorative Dentistry, São José dos Campos School of Dentistry, São Paulo State University, São Paulo, Brazil

\section{Eduardo Bresciani}

Assistant Professor, Department of Restorative Dentistry, São José dos Campos School of Dentistry, São Paulo State University, São Paulo, Brazil

\section{Cesar Rogério Pucci}

Assistant Professor, Department of Restorative Dentistry, São José dos Campos School of Dentistry, São Paulo State University, São Paulo, Brazil

\section{CORRESPONDING AUTHOR}

Sérgio Eduardo de Paiva Gonçalves, Associate Professor, Department of Restorative Dentistry, Avenida Engenheiro Francisco José Longo 777, Jardim São Dimas, São José dos Campos, São Paulo, CEP: $12245-$ 000, Brazil, Phone: +55(12)39479051, Fax: +55(12)39479010 e-mail: sergio@fosjc.unesp.br 
